\title{
Innovation of E-Commerce Service Mode in the Era of Big Data

\author{
Feng Liao ${ }^{1}$ and Yuxin $\mathrm{Yu}^{2}$ \\ ${ }^{1}$ Jiangxi Technical College of Manufacturing, Nanchang,330095 \\ ${ }^{2}$ Jiujiang Vocational University, Jiujiang,332000
}

Keywords: Big Data; E-commerce; Service Mode; Innovation Strategy

\begin{abstract}
With the development of information technology, the information age is becoming more and more powerful in data processing and analysis. Data has penetrated into all walks of life and has become an important factor in production. In the era of big data, E-commerce has also undergone great changes. How to use the huge data to provide better service experience is the key to the innovation of E-commerce service model in the future. The global information and data show explosive growth, and people's living environment and working conditions have changed dramatically. How to make good use of these big data, so that it better serve E-commerce trade activities become a hot topic. Based on this, this paper first describes the definition and characteristics of big data. Then, it introduces the general situation of E-commerce development under the background of big data, and focuses on the innovation of E-commerce service model. Through the new network dissemination and service model, people have more understanding and understanding of E-commerce in the era of big data.
\end{abstract}

\section{Introduction}

In recent years, with the advent of the era of big data, China's E-commerce services in constant innovation, and its coverage has gradually enriched. Especially in recent years, with the popularity of smart phones and the widespread use of mobile terminals, all kinds of E-commerce services are in the stage of rapid development. However, we are not satisfied with the status quo. The fierce competition in the market and the constant change of the economic situation are testing the enterprises with E-commerce as the main service. In today's global big data era, companies want to really stand at the peak, in addition to constantly updating, mining, statistical data value, but also focus on the future vision, able to control the big data bring good. And it has a unique way of thinking and innovative e-commerce service concept. It can be said that without innovation and long-term thinking, there will be no progress. Without the idea of innovation and progress, one can always see only half of the scenery on the mountain, but for the summit, it cannot be touched. With the maturity of the E-commerce system in China, big data has become the key model affecting the development of E-commerce. How to complete the innovation of E-commerce service model in the background of big data era has become one of the key factors of E-commerce enterprises and the development of E-commerce in china.

\section{Basic Overview of Big Data}

Big data is the product of the times in the background of the rapid development of information technology. It is also called "huge amount of data" with high growth rate and diversity. It requires new processing models to achieve greater decision-making power and insight, and then become an information asset with process optimization capabilities.

Viktor Mayer-Schönberger and Kenneth Cukier have pointed out in "big data times", big data has $4 \mathrm{~V}$ characteristic, including Volume, Velocity, Variety, Value. With the advent of the cloud era, big data has attracted more and more attention from the industry. However, the strategic significance of big data is not to grasp the huge amount of data information, but to benefit from the processing and processing of meaningful data.

Big data is, in a sense, a frontier technology for data analysis. In other words, big data technology is the rapid acquisition of valuable information from various types of data. Its core value 
is to analyze vast amounts of data and select valuable ones for storage and backup. Compared with other technologies, big data has the characteristics of cheapness, speed and optimization.

Big data applications are very broad, can be divided into big data technology, big data engineering, big data science and big data applications. From the current scientific and technological and social environment, we pay more attention to the big data technology and big data applications in two areas. The rapid development of big data technology is considered another disruptive technological innovation in the Internet industry.

\section{The Transformation of E-Commerce in the Era of Big Data}

E-commerce is the use of Internet information technology to build an electronic business platform, the traditional commercial transactions into online shopping process. No direct contact between the two sides of the transaction, breaking the traditional trading time and space constraints. E-commerce has become a new mode of business development, and has received great attention from various industries. With the arrival of the era of big data, E-commerce business model gradually changes to data information. In all aspects of the electricity supplier operators, the use of big data for professional analysis. Through effective information processing technology, we can adjust the type and quantity of the goods according to the market demand. This can not only meet the needs of consumers, but also maximize the use of commodity resources.

E-commerce Business Philosophy is Changing. In the era of big data, E-commerce can analyze people's transactions through data and information. Targeted measures are taken for consumer preferences. Big data can be displayed by consumer web browsing records, consumer habits, and purchase records and other information. According to the information recorded by the database, consumers can provide similar products, thus enabling consumers to save time of browsing and promote the completion of commodity transactions. This makes E-commerce marketing concept has changed, through the use of big data can achieve better development of E-commerce.

Diversified Development of E- Commerce Model. E-commerce model refers to the operation of the network platform under certain technical conditions, and ultimately to obtain economic profit model. With the expansion of its scope of application and the continuous development of information services, E-commerce model is constantly changing and innovation. At this stage, there are several modes: B2C model, e-commerce between enterprises and consumers. B2B mode, electricity supplier activities between enterprises. C2C model, electricity supplier activities between consumers. $\mathrm{O} 2 \mathrm{O}$ mode, offline business activities between entities and networks. And in the era of big data, E-commerce has emerged a new model, that is, through the operator to enable the two sides to achieve the purpose of the transaction.

\section{Innovation of E- Commerce Service Model in Big Data Era}

More Accurate Information Retrieval. With the progress of the times, E-commerce plays a more and more important role in people's daily life and becomes a new model of enterprise marketing. Big data technology also provides new business opportunities for enterprise innovation. Consumers are often difficult to find the goods they need in the face of massive network data, then the electricity supplier can through the data collection and analysis, according to the different needs of different users of the user is subdivided into different categories, and for different categories of users to provide personalized service. This requires the electricity supplier to provide consumers with more accurate information retrieval services, the product category distinction. In the larger category, and then subdivided, so that consumers in the search can quickly find matching goods through key words, greatly saving consumers in a complex network environment to pick the product of time.

Reduce the Cost of Commodity Circulation Transactions. With the advent of e-commerce, people are no longer bound by space and time, nor will there be many restrictions on traditional shopping. They can do shopping online anytime and anywhere. For businesses, they can reach more consumers in unit time. The Internet has transformed the world into a "global village", a business 
that faces consumers all over the world. In the face of different regions and different types of consumers, businesses can make data analysis by collecting user information, in order to find matching buyers, greatly reducing the intermediate links of commodity circulation, reduce the cost of commodity circulation, reduce unnecessary waste of production.

Promote Differentiated Competition Electricity Supplier Enterprises. With the arrival of the information age, the marketing mode of enterprises is changing constantly, and the competition among enterprises is becoming more and more fierce. At present, China's E-commerce enterprises are facing two major issues of cost competition and homogenization of competition. The arrival of big data era can bring new opportunities for E-commerce enterprises, and provide new ways for industry competition. Enterprises can better grasp customer information through big data analysis, and make their marketing model more precise, so as to improve marketing efficiency. At the same time, to reduce the cost of sales, E-commerce enterprises to obtain more profit space, and promote their differentiation competition.

\section{Conclusion}

At present, with the arrival of the era of big data, it is an opportunity and a challenge for the development of E-commerce. Through the analysis and processing of data information, the electricity supplier enterprises can provide new service models according to the different needs of users, and promote the further development of E-commerce. With the continuous promotion of big data, cloud storage and big data processing technology have gradually become the core competitiveness of E-commerce enterprises. The growing mass of information and data brings opportunities and challenges to enterprises. Through the analysis and application of data, it brings more new ideas and new models to the innovation of marketing operation mode. With the popularization of big data, how to dig out more valuable information through the technical means to serve the E-commerce enterprises, and then meet the daily needs of people, also needs to be constantly excavated and discussed

\section{References}

[1] Ismail M, Ibrahim M M, Sanusi Z M, et al. Data Mining in Electronic Commerce: Benefits and Challenges[J]. International Journal of Communications Network 、 System Sciences, 2015, 08(12):501-509.

[2] Jamali S K, Samadi B, Gharleghi B. Factors Influencing Electronic Commerce Adoption: A Case Study of Iranian Family SMEs[J]. 2015, 6:207-221.

[3] Agwu E M, Murray P J. Empirical Study of Barriers to Electronic Commerce Adoption by Small and Medium Scale Businesses in Nigeria[J]. International Journal of Innovation in the Digital Economy, 2015, 6.

[4] Yoon H S, Occeña L G. Influencing factors of trust in consumer-to-consumer electronic commerce with gender and age[J]. International Journal of Information Management, 2015, 35(3):352-363.

[5] Nikishin A F, Pankina T V. The problem of involvement of clients in electronic commerce[J]. 2015:15-17.

[6] Davidson A E, Schwarzhoff K L, Herri G, et al. Method and apparatus for viewing electronic commerce-related documents[J]. 2016.

[7] Domínguez J, Velando A. How purchase intention consummates purchase behaviour: the stochastic nature of product valuation in electronic commerce[J]. Behaviour 、 Information Technology, 2015, 34(1):57-68.

[8] Moshkovich H, Mechitov A, Olson D. Infusion of Electronic Commerce into the Information Systems Curriculum[J]. Journal of Computer Information Systems, 2016, 46(1):1-8.

[9] Lee S Y T, Phang C W. Leveraging social media for electronic commerce in Asia: Research areas and opportunities[J]. Electronic Commerce Research 、 Applications, 2015, 
14(3):145-149.

[10] Karch A, Rosenthal A. Vertical Diffusion and the Shifting Politics of Electronic Commerce[J]. State Politics 、 Policy Quarterly, 2016, 6(1).

[11] Awa H O, Awara N F, Lebari E D. Critical factors inhibiting Electronic Commerce (EC) adoption in Nigeria[J]. Journal of Science 、 Technology Policy Management, 2015, 6(2):143-164.

[12] Susanto H T A, Chang Y. Determinants of initial trust formation in electronic commerce acceptance in Indonesia[C]// Systems, Process and Control. IEEE, 2015:96-100. 